\title{
PENGARUH MODEL IKRAR TERHADAP HASIL BELAJAR SISWA MTS NURUL SA'ADAH
}

\author{
Riza Mahfidia Putri \\ STKIP PGRI Sidoarjo, putririza307@gmail.com \\ Risdiana Chandra Dhewy \\ STKIP PGRI Sidoarjo, chandra.statsitika.its@gmail.com \\ Intan Bigita Kusumawati \\ STKIP PGRI Sidoarjo, bigita.intan@gmail.com
}

\begin{abstract}
Abstrak
Dalam pembelajaran k13, pembelajaran yang digunakan adalah pembelajaran yang berpusat pada siswa, siswa dituntut untuk aktif mengembangkan pengetahuannya sendiri. Penelitian ini bertujuan untuk mengetahui hasil belajar siswa pada materi bangun ruang sisi datar (kubus dan balok) dengan menggunakan model pembelajaran IKRAR. Model pembelajaran IKRAR merupakan model pembelajaran yang sesuai dengan paham konstruktivis dimana dalam proses pembelajaran siswa diberikan suatu masalah matematika dan siswa dituntut aktif dalam mengkonstruksi konsep yang dipelajari. Penelitian ini dilaksanakan pada tahun ajaran 2018/2019 di MTS Nurul Sa'adah pada kelas VIII-C dengan jumlah siswa sebanyak 25 siswa. Jenis penelitian yang digunakan adalah kuantitatif yang terdiri dari 2 kali pertemuan pembelajaran dan 1 hari pertemuan untuk evaluasi hasil belajar siswa. Rancangan yang digunakan dalam penelitian ini adalah One Shoot Case Study. Pengambilan sampel dalam penelitian ini menggunakan teknik Simple Random Sampling. Penelitian ini menggunakan instrumen lembar observasi guru, lembar observasi siswa dan lembar observasi soal tes. Teknik analisis data yang digunakan dalam penelitian ini adalah uji asumsi klasik dilanjutkan menggunakan analisis regresi linier sederhana. Pada hasil penelitian ini uji t diperoleh $t_{\text {hitung }}>t_{\text {tabel }}(4,166>2,069)$ sehingga $H_{0}$ ditolak. Dengan demikian dapat disimpulkan bahwa ada pengaruh antara model pembelajaran IKRAR terhadap hasil belajar siswa.
\end{abstract}

Kata kunci: Model Pembelajaran IKRAR. Hasil Belajar

\begin{abstract}
In k13 learning, learning used is student-centered learning, students are required to actively develop their own knowledge. This study aims to find out the student learning outcomes in the material to construct a flat side space (cubes and beams) using the IKRAR learning model. IKRAR learning model is a learning model that is in accordance with constructivist understanding where in the learning process students are given a mathematical problem and students are required to be active in constructing the concepts learned. This research was conducted in the 2018/2019 school year at MTS Nurul Sa'adah in class VIII-C with a total of 25 students. The type of research used is quantitative which consists of 2 learning meetings and 1 day meeting to evaluate student learning outcomes. The design used in this study is One Shoot Case Study. Sampling in this study uses Simple Random Sampling. This study uses the instruments of teacher observation sheets, student observation sheets and observation sheets of test questions. The data
\end{abstract}


analysis technique used in this study is the classic assumption test followed by using simple linear regression analysis. On the results of this study t test is obtained $\mathrm{t}$ test $>\mathrm{t}$ table $(4,166>2,069)$ so that $\mathrm{H} 0$ is rejected. Thus it can be concluded that there is an influence between IKRAR learning models on student learning outcomes.

Keywords: IKRAR Learning Model, Learning outcomes 


\section{PENDAHULUAN}

Slameto (dalam Afandi dkk, 2013) belajar merupakan suatu proses usaha yang dilakukan seseorang untuk memperoleh perubahan tingkah laku yang baru secara menyeluruh, sebagai hasil dari pengalaman sendiri dalam berinteraksi dengan lingkungan. Belajar adalah melakukan suatu kegiatan untuk menimbulkan suatu perubahan yang lebih baik dari sebelumnya. Jadi belajar adalah kegiatan yang menimbulkan perubahan melalui suatu pengalaman.

Berdasarkan penjelasan sebelumnya, belajar berarti kegiatan yang menimbulkan perubahan pada diri seseorang. Belajar sudah menjadi suatu kebutuhan dasar bagi manusia untuk memenuhi kebutuhan diri, serta menyesuaikan dengan ilmu pengetahuan yang sudah semakin berkembang pesat. Dalam kegiatan belajar mengajar, guru yang menciptakan suatu pembelajaran pada siswa.

Dalam kegiatan pembelajaran, Guru hanya sebagai pembimbing dan fasilitator untuk siswa, selebihnya siswa sendiri yang harus aktif dalam pembelajaran agar siswa dapat memahami materi serta mengeluarkan kemampuan yang mereka miliki. Itu berarti pembelajaran sebaiknya lebih berpusat pada siswa. Selanjutnya guru memberikan motivasi agar siswa mempunyai kemauan untuk belajar lebih maksimal. Sanjaya (dalam Afandi dkk,
2013) mengemukakan bahwa hasil belajar adalah tingkah laku yang dirumuskan dalam bentuk kemampuan dan kompetensi yang dapat diukur atau dapat ditampilkan melalui performance siswa. Jadi hasil belajar adalah suatu perbuatan yang dapat dilihat dalam bentuk kemampuan seseorang setelah melakukan pembelajaran.

Pada saat peneliti melakukan kegiatan magang di sekolah, dalam proses pembelajaran seringkali siswa menghadapi berbagai kendala salah satunya yaitu sulit memahami soal tentang pemecahan masalah yang diberikan dalam pelajaran matematika. Model pembelajaran yang tepat salah satunya yaitu Inisiasi, Konstruksi - Rekonstruksi, Aplikasi, Refleksi (IKRAR) yang akan diterapkan di MTS Nurul Sa'adah. Sudiarta (dalam Husna dkk, 2018) IKRAR merupakan model pembelajaran yang dikembangkan melalui refleksi mendalam terhadap kelemahan model pembelajaran berbasis pemecahan masalah matematika konvensional sebelumnya. Model pembelajaran IKRAR adalah model pembelajaran yang cenderung memberi suatu masalah matematika terhadap siswa. IKRAR meliputi Inisiasi, KontruksiRekontruksi, Aplikasi, Refleksi yang mana Inisiasi yaitu awal proses dalam diri siswa untuk memperoleh gambaran terhadap apa yang akan dipelajari, Kontruksi- 
Rekontruksi yaitu kegiatan pembentukan pengetahuan dan penggunaan pengetahuan yang sudah diketahui sebelumnya, Aplikasi yaitu penerapan dalam dunia nyata, dan Refleksi yaitu melihat kembali proses pembelajaran yang telah dilakukan.

Ada beberapa penelitian yang menunjukan hasil positif pada pembelajaran dengan menggunakan model pembelajaran IKRAR diantaranya yaitu penelitian Iffana (2017) hasil belajar siswa mencapai 82,23\% lulus KKM".

Untuk mengembangkan dan menggunakan model matematis, penelitian ini menggunakan penelitian kuantitatif, dengan menggunakan Pre-Experimental Design yaitu One-shot Case Study. Tahap pertama semua kelompok diberikan penerapan model pembelajaran Inisiasi Konstruksi-Rekonstruksi Aplikasi Refleksi (IKRAR) dalam pembelajaran, utnuk tahap kedua setiap kelompok diberikan lembar tes (posttest). One-shot Case Study dapat dilukiskan sebagai berikut:

\begin{tabular}{|lll|}
\hline $\mathrm{X}$ & $\longrightarrow$ \\
\hline
\end{tabular}

Keterangan:

$\mathrm{X}=$ Perlakuan yang berupa pembelajaran matematika dengan model pembelajaran Inisiasi KonstruksiRekonstruksi Aplikasi Refleksi (IKRAR)

$\mathrm{Y}=$ Hasil belajar setelah menggunakan model pembelajaran
Populasi yang digunakan adalah semua siswa kelas VIII MTS Nurul Sa'adah tahun 2018/2019. Pengambilan sampel menggunakan teknik random sampling yaitu pengambilan sampel secara acak antara kelas VIII-A sampai VIII-E. Dalam penelitian ini diambil sampel dari kelas VIII-C. Teknik pengumpulan data pertama adalah pelaksaan metode observasi dengan cara mengamati, memberi skor pada lembar aktivitas guru dan aktivitas siswa selama kegiatan pembelajaran menggunakan Inisiasi Konstruksi-Rekonstruksi Aplikasi Refleksi (IKRAR). Untuk tahap kedua menggunakan metode tes setelah penerapan model pembelajaran Inisiasi Konstruksi-Rekonstruksi Aplikasi Refleksi (IKRAR) dalam pembelajaran di kelas.

\section{HASIL DAN PEMBAHASAN}

Instrumen yang digunakan dalam penelitian ini yaitu lembar observasi guru, lembar observasi siswa yang diberikan kepada guru dan lembar tes yang akan diberikan kepada 25 siswa di kelas VIII-C di MTS Nurul Sa'adah. Data penelitian sebagai berikut:

Tabel 1. Data Penelitian

\begin{tabular}{cccc}
\hline No. & Nama & X & Y \\
\hline 1 & AR & 53 & 80 \\
\hline 2 & CA & 52 & 85 \\
\hline 3 & DFA & 53 & 85 \\
\hline
\end{tabular}




\begin{tabular}{cccc}
\hline No. & Nama & X & Y \\
\hline 4 & DM & 52 & 75 \\
\hline 5 & FFR & 52 & 80 \\
\hline$\bullet$ & $\bullet$ & $\bullet$ & $\bullet$ \\
\hline$\bullet$ & $\bullet$ & $\bullet$ & $\bullet$ \\
\hline$\bullet$ & $\bullet$ & $\bullet$ & $\bullet$ \\
\hline 25 & ZE & 53 & 80 \\
\hline
\end{tabular}

Setelah data terkumpul, data akan dianalisis menggunakan analisis regresi linier sederhana. Namun sebelum itu hasil dari data tersebut harus diuji terlebih dahulu menggunakan uji normalitas dan diperoleh nilai Kolmogorov-Smirnov hitung $=0,156$ dan nilai KolmogorovSmirnov tabel $=0,275$. Hasil perhitungan diperoleh $0,156<0,275$ sehingga dapat disimpulkan residual berdistribusi normal. Selanjutnya menggunakan uji heteroskedastisitas diperoleh $t_{\text {hitung }}=$ 1,795. Hal ini menunjukkan $-1,795<$ 2,069 sehingga dapat disimpulkan residual bersifat homogen. Kemudian menggunakan uji autokorelasi diperoleh nilai dU $(1,4537)<\mathrm{d}$ hitung $(1,984)<4$ dU $(2,5463)$ maka terima $\mathrm{H}_{0}$. Kriteria uji parsial dengan kriteria sebagai beriku: $\mathrm{H}_{0}$ ditolak apabila $t_{\text {hitung }}>\mathrm{t}_{\text {tabel}}$, dan diperoleh $\mathrm{t}_{\text {hitung }}=4,166$ dan $\mathrm{t}_{\text {tabel }}=2,069$. Karena nilai $t_{\text {hitung }}>\mathrm{t}_{\text {tabel }}$ sehingga $\mathrm{H}_{0}$ ditolak. Dengan demikian, ada pengaruh yang signifikan dengan menggunakan model pembelajaran IKRAR terhadap hasil belajar siswa.

Dalam peneletian pengambilan data dilaksanakan tiga kali pertemuan yaitu tanggal 14, 17, 18 Juni 2019. Pertemuan pertama dan kedua pemberian pembelajaran menggunakan model pembelajaran IKRAR. Pertemuan ketiga melaksanakan post tes.

Dalam pelaksanaan penelitian, menunjukkan kontribusi variabel $\mathrm{X}$ terhadap $\mathrm{Y}$ diperoleh $43 \%$ dan sisanya $67 \%$ ditentukan varabel lain. Sehingga ada pengaruh signifikan setelah menggunakan model pembelajaran IKRAR.

\section{SIMPULAN}

Berdasarakan hasil peneletian model pembelajaran IKRAR terhadap hasil belajar siswa diperoleh t-hitung $(4,166)>$ t-tabel (2,069) dengan nilai signifikan diperoleh $0,000<0,05$ sehingga tolak $\mathrm{H}_{0}$ dan $\mathrm{H}_{1}$ diterima. Sedangkan kontribusi variabel X terhadap Y diperoleh $43 \%$ dan sisanya $67 \%$ ditentukan varabel lain. Maka dapat disimpulkan ada pengaruh model pembelajaran IKRAR terhadap hasil belajar siswa. 
Pengaruh Model IKRAR...

\section{DAFTAR PUSTAKA}

Afandi, M., dkk. (2013). Model dan Metode Pembelajaran di Sekolah. Semarang: UNISSULA Press.

Husna, U. (2018). Studi Pendahuluan Tentang Pengembangan Model Pembelajaran Ikrar (Inisiasi, Konstruksi-Rekonstruksi, Aplikasi, Refleksi) Untuk Meningkatkan Kemampuan Pemecahan Masalah Matematika. JOURNAL OF RESEARCH IN EDUCATION UNIVERSITAS ADIWANGSA JAMBI, 1(1), 40-44.

Iffana, A. F. (2017). Penerapan Model Pembelajaran Ikrar Pada Materi Kerucut Pada Siswa Kelas IX SMP. MATHEdunesa, 2(6), 328337. 